\title{
O PROTAGONISMO JUVENIL EM PRÁTICAS DE EDUCAÇÃO AMBIENTAL EM UMA ESCOLA PÚBLICA DO NORDESTE PARAENSE, BRASIL
}

\section{YOUTH PROTAGONISM IN ENVIRONMENTAL EDUCATION PRACTICES IN A PUBLIC SCHOOL IN NORTHEASTERN OF PARÁ, BRAZIL}

\author{
João Rodrigues Silva ${ }^{1}$ \\ Sabas Mescouto e Silva ${ }^{2}$ \\ Miguel Braga ${ }^{3}$
}

Data de submissão: 05.09 .2021

Data de aprovação: 20.12 .2021

O presente ensaio etnográfico destaca o protagonismo juvenil de estudantes de ensino médio de uma escola pública do município de Primavera, estado do Pará, na resolução de situações-problemas reais que envolvem a relação homem e natureza, mais precisamente a degradação ambiental de nascentes. O referido ensaio registra a experiência da Escola Manoel Lobato na promoção de uma aprendizagem diferenciada que priorize a construção dos aspectos formativos dos jovens por meio de práticas de Educação ambiental que estimulem suas potencialidades e contribuições no contexto socioambiental em que vivem.

Com a reestruturação do Novo Ensino Médio a partir das alterações na Lei de Diretrizes e Bases da Educação (LDB) e a formulação da Base Nacional Comum Curricular (BNCC), o protagonismo juvenil passou a ser incentivado e destacado como uma das principais premissas (BRASIL, 2018). Essa formação do jovem deve contemplar os aspectos físicos, cognitivos e socioeconômicos, e potencializar sua capacidade de liderança e resolução de situações-problemas reais (SANTOS e GOMES, 2016).

O município de Primavera está inserido no nordeste paraense, uma região considerada como a mais antiga fronteira de colonização do estado do Pará, cuja paisagem atual, marcada por um cenário de erosões, rios e igarapés assoreados, resulta de ações antropogênicas como a agricultura, exploração madeireira, produção mecanizada, projetos agropastoris e minerários (CORDEIRO et al., 2017). O desmatamento também avançou sobre as encostas e matas ciliares, áreas que protegem e aumentam a taxa de infiltração de água no solo propiciando o afloramento do lençol freático na forma de nascentes. Essas Áreas de Preservação Permanente (APP) precisam ser protegidas, e recuperadas em caso de degradação (SILVA et al., 2008). Estudos indicam que o avanço contínuo do desmatamento na Amazônia pode levar a uma redução precoce de $55 \%$ a $70 \%$ no volume anual de precipitação na região e que ações de reflorestamento são cruciais para a reconstituição desse equilíbrio no regime de chuvas (BAUDENA et al., 2021).

Diante da carência e indisponibilidade de dados oficiais sobre o número de nascentes urbanas e rurais, localização e estado de conservação, a escola Manoel Lobato criou o Projeto Trilha da Águas com o objetivo de avaliar as condições socioambientais acerca dos recursos naturais e sensibilizar o poder público municipal sobre a necessidade de conhecê-los e preservá-los. Com as ações promovidas pela escola e alunos, as nascentes foram identificadas, classificadas, georreferênciadas, mapeadas e caracterizadas quanto ao seu estado de conservação.

\footnotetext{
${ }^{1}$ Professor de Biologia de ensino médio (biologia) da rede pública de ensino- SEDUC-PA. Graduado em biologia- UFPA (2007) e Mestre em biologia ambiental- UFPA (2013). E-mail: jrsilvabio@gmail.com.

${ }^{2}$ Professor de Geografia na rede estadual de Educação, SEDUC - PA. Especialista em Geografia da Amazônia, Faculdade Integrada Brasil Amazônia (FIBRA), Campus Belém - PA. E-mail: geo_sabas@yahoo.com.br.

${ }^{3}$ Doutor em Química, Universidade Federal do Pará, Campus Belém. Professor EBTT do Instituto Federal do Pará (Campus de Bragança). E-mail: miguel.braga@ifpa.edu.br.
} 
Em sua fase inicial (2017-2018), as propostas do projeto foram apresentadas à comunidade escolar na forma de palestras. Os critérios adotados para participação dos alunos seria o interesse, o histórico de boa conduta escolar e a obtenção de bom desempenho em disciplinas como Língua Portuguesa, Matemática, Ciências, Geografia, Biologia, Física e Química. De acordo com o perfil e interesse dos alunos, eles foram treinados por meio de oficinas: técnicas básicas de fotografia científica ambiental; técnicas de georreferenciamento; aplicação e análise do protocolo macroscópico de avaliação ambiental de nascentes; redação científica.

$\mathrm{Na}$ etapa pós-campo, foram avaliados os métodos mais adequados para adotar no processo de recuperação de 02 das nascentes que apresentaram níveis críticos de conservação. Em 2019, um mutirão de limpeza de uma das nascentes contou com a participação de professores, alunos, de integrantes do Projeto social "Força Jovem" e de funcionários da Secretaria Municipal de Meio Ambiente. Em 2020, em decorrência da Pandemia de COVID 19, a etapa de revitalização das nascentes, a partir do plantio de mudas de espécies nativas (doadas por viveiristas locais), ocorreu com uma equipe reduzida. Nesse mesmo ano, a área já revitalizada com o plantio, foi severamente atingida por um incêndio, com fortes indícios de ter sido criminoso. Em 2021, o trabalho de revitalização se voltou para a mesma área atingida pelo fogo e contou com a parceria de viveiristas locais, órgão ambiental municipal, alunos e ex-alunos da escola Manoel Lobato.

Nesse contexto, estratégias de revitalização e preservação de nascentes pode ser o ponto de partida para despertar uma consciência de uso racional da água, bem como da preservação dos mananciais, principalmente, no momento que se avizinha uma crise hídrica e num cenário que aponta para a possibilidade de drástica redução no volume anual de precipitação na região amazônica.

\section{REFERÊNCIAS}

BAUDENA, M. et al. Effects of land-use change in the Amazon on precipitation are likely underestimated. In Global Change Biology, p. 1- 8, July 2021. DOI: 10.1111/gcb.15810. Disponível em: https://doi. org/10.1111/gcb.15810.111/gcb.15810. Acesso em: 24 ago. 2021.

BRASIL. MINISTÉRIO DA EDUCAÇÃO; CONSELHO NACIONAL DOS SECRETÁRIOS ESTADUAIS DE EDUCAÇÃO; FÓRUM NACIONAL DOS CONSELHOS. Guia de implementação do Novo Ensino Médio. Brasilia: [s.n.], 2018.

CORDEIRO, I. M. C. C.; ARBAGE, M. J. C.; SCHWARTZ, G. Nordeste do Pará: Configuração atual e aspectos identitários. In: CORDEIRO, I. M. C. C., et al. Nordeste Paraense: Panorama geral e uso sustentável das florestas secundárias. Belém: EDUFRA, 2017. Cap. 1, p. 19-58.

SANTOS, H. F. D. S.; GOMES, J. J. O Protagonismo Juvenil como Processo Educativo e Direito Humano Positivado no Ordenamento Jurídico Brasileiro. Revista de Direitos e Garantias Fundamentais, Vitória, 17, n. 2, JUL/DEZ 2016. p. 465-492.

SILVA, M. P. S. D.; BARBOSA, T. R. L.; BARROSO, D. G. Preservação de Nascentes. Niterói: Programa Rural, v. 8, 2008. 

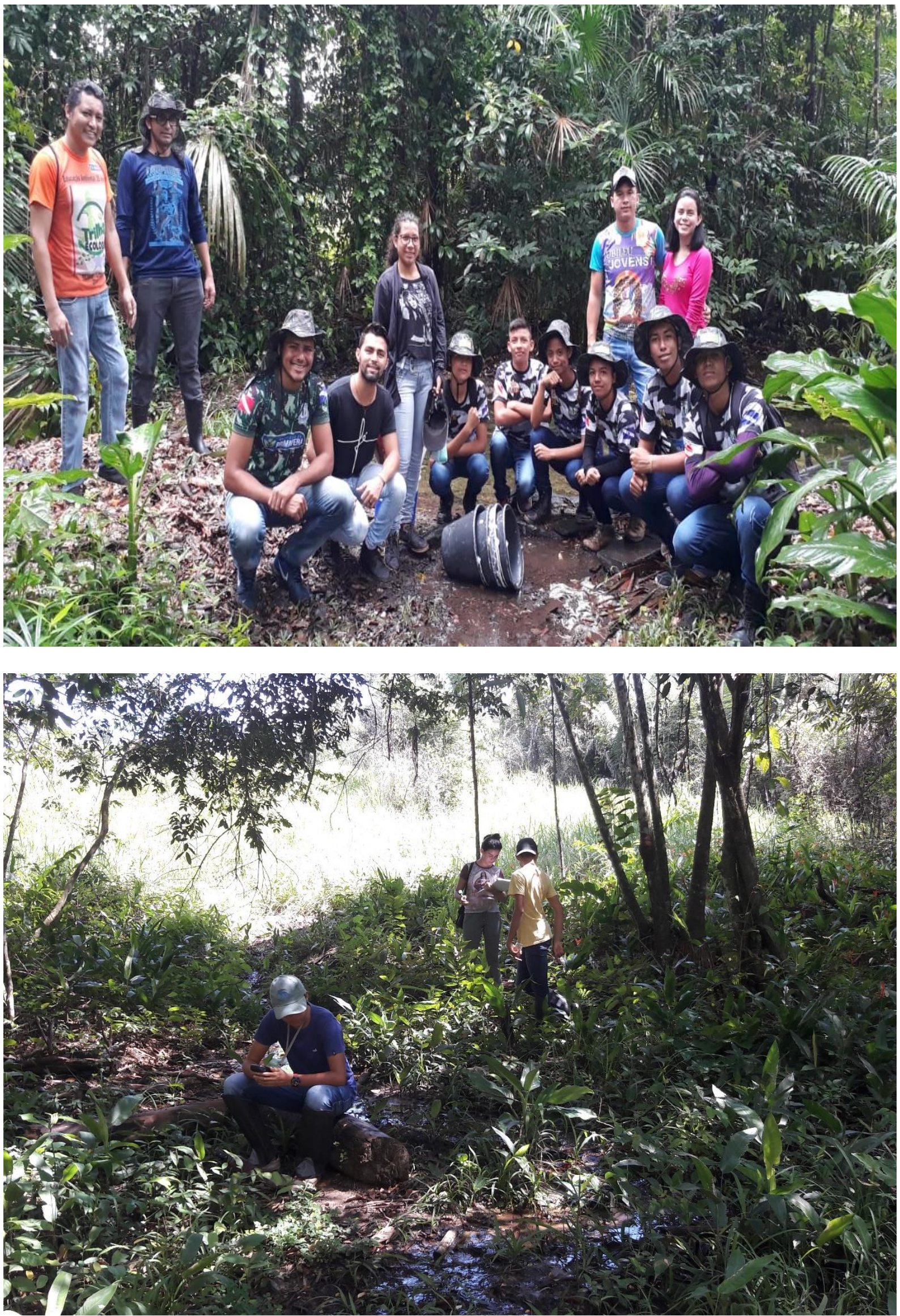

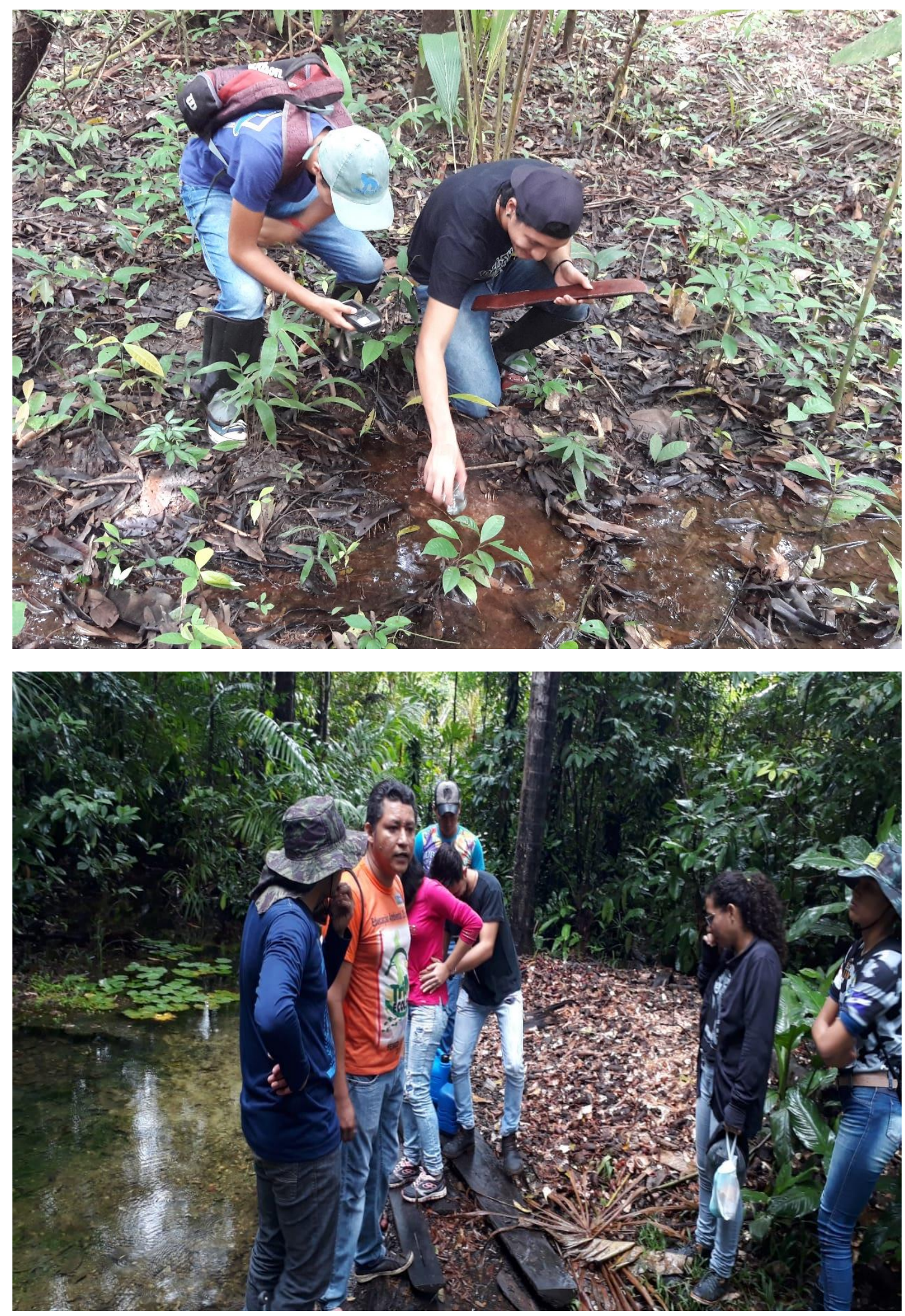

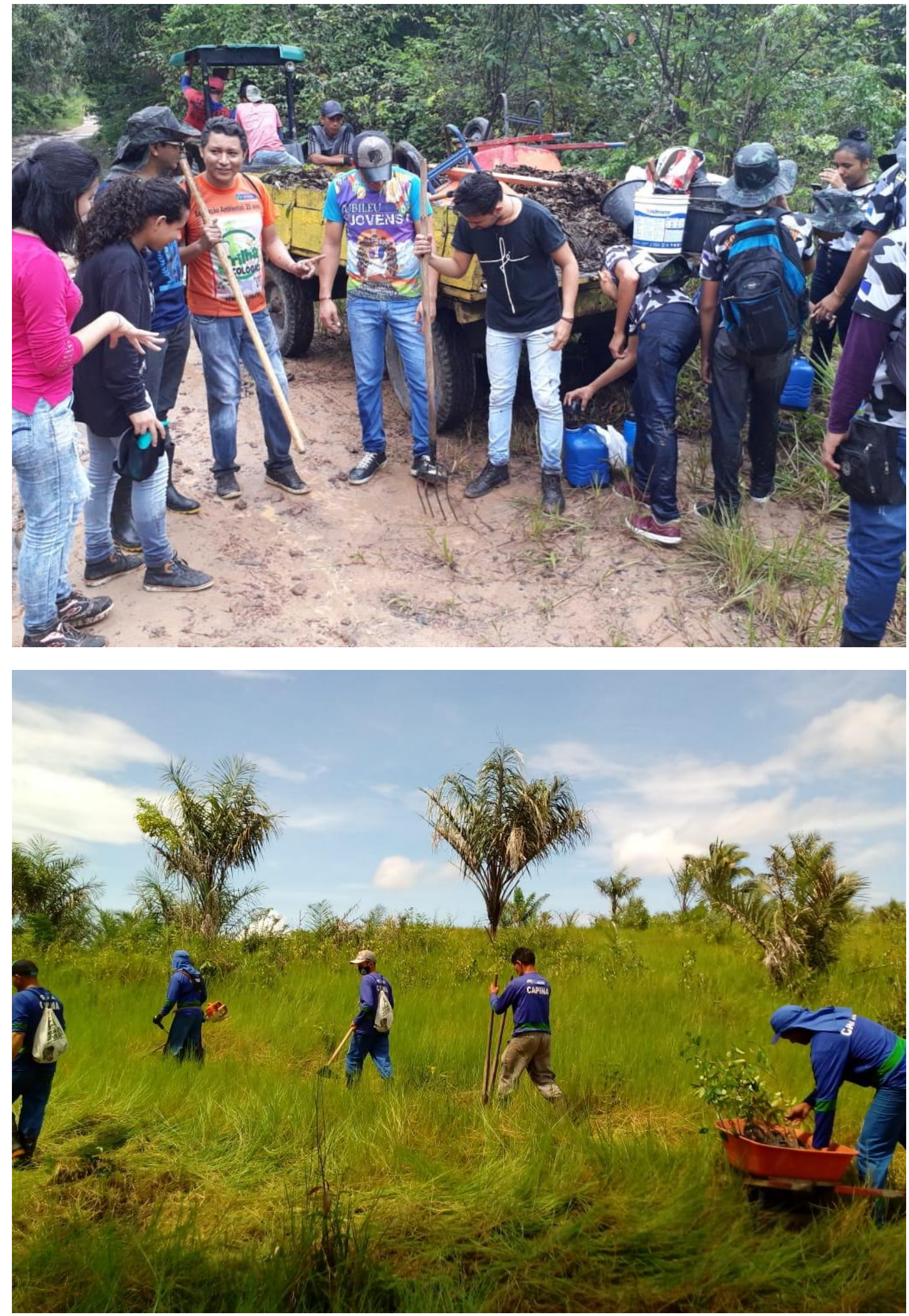

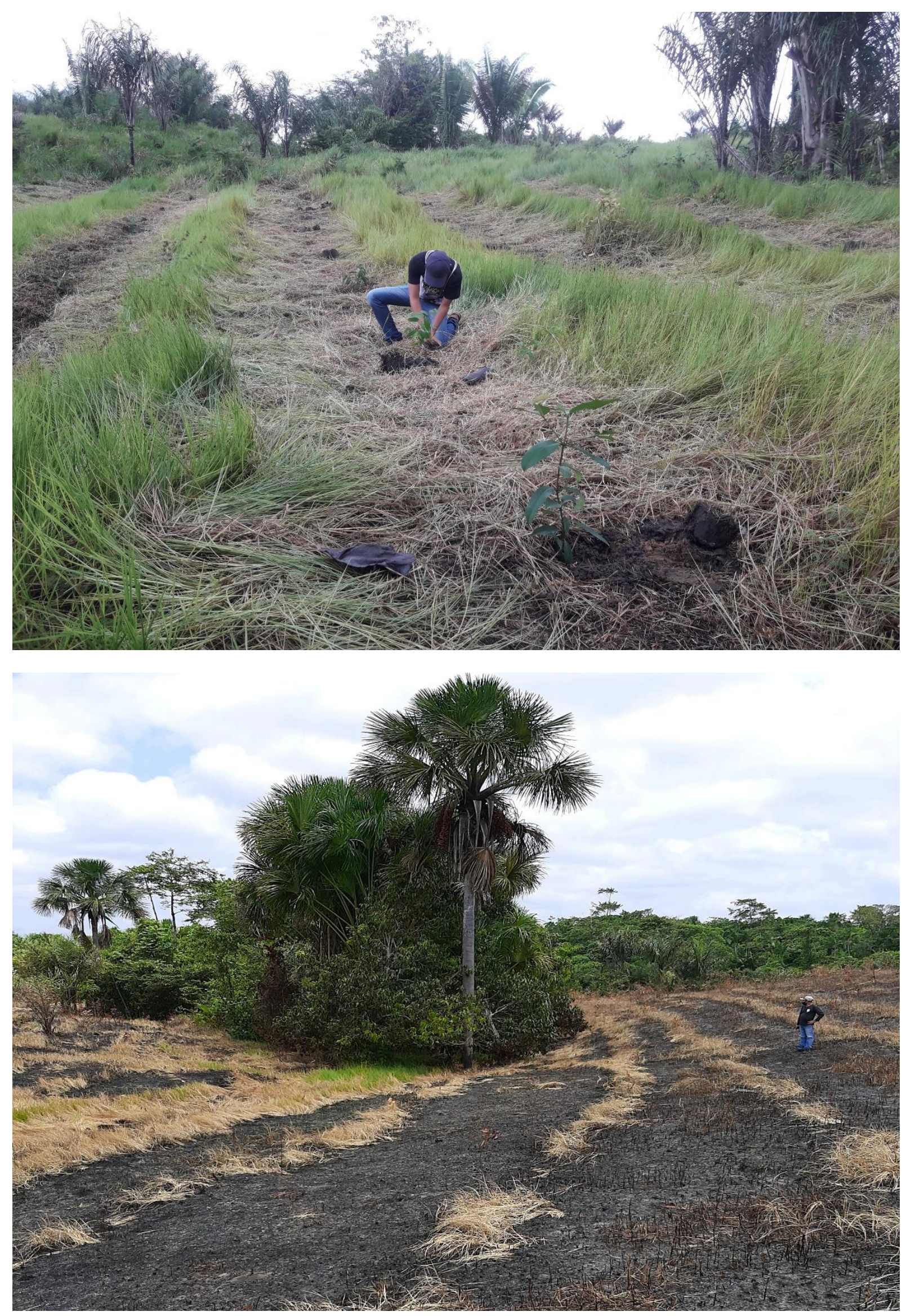

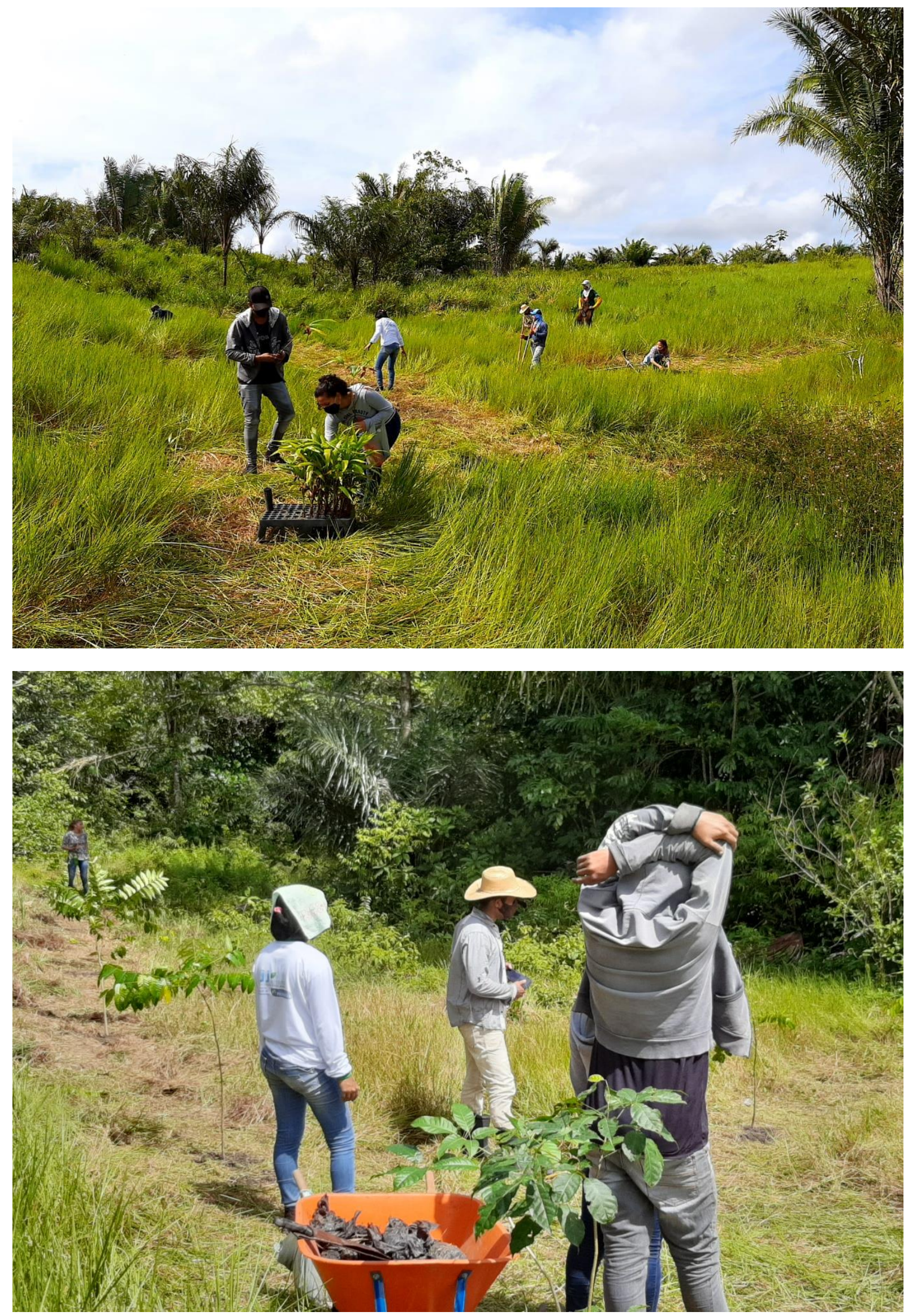